Case Report

\title{
Repair of Consecutive Cases of Hypospadias at 37 Military Hospital
}

\author{
Ben Adusei, Sunny Duodo Mante, Joshua Amegbor, Paul Kodjo Yegbe \\ Urology Unit, Department of Surgery, 37 Military Hospital, Accra, Ghana \\ Email address: \\ Baks02016@yahoo.com (B. Adusei)
}

To cite this article:

Ben Adusei, Sunny Duodo Mante, Joshua Amegbor, Paul Kodjo Yegbe. Repair of Consecutive Cases of Hypospadias at 37 Military Hospital. International Journal of Clinical Urology. Vol. 4, No. 2, 2020, pp. 77-80. doi: 10.11648/j.ijcu.20200402.20

Received: September 24, 2020; Accepted: October 14, 2020; Published: October 30, 2020

\begin{abstract}
The outcome of hypospadias repair usually will depend on the skills of the surgeon, the case load and the type of repair done. We report our results from 37 Military hospital in Accra, Ghana. Hypospadias is one of the commonest urologic congenital anomalies. It is associated with three anatomical anomalies: 1 . an abnormal ventral opening of the urethral meatus; 2 . Ventral curvature (chordae) of the penis; 3. A hooded foreskin. Method: This was a retrospective study of patients who had hypospadias repair between the periods of 2010 to 2017 at the 37 Military hospital. Data of patients who had hypospadias repair at the urology unit was collected. A total of 51 patients were studied out of a total of 1467 surgeries done within that period. Data on patient age, type of hypospadias, type of repair, complications were recorded. Repair was done for patients older than 6 months. Types of repair for urethral construction included; Glans Approximation procedure, (GAP); meatal advancement and glanuloplasty incorporated, (MAGPI); tubularized incised plate urethroplasty, (TIPU); Mustarde'; buccal mucosal tube tunnelled urethroplasty. For the correction of the chordae, a dermal graft was the main procedure of choice. Results: The commonest age of presentation and repair is before the age 5 years, $54.9 \%(28 / 51)$. The commonest types of hypospadias at presentation is coronal. The commonest complication is urethrocutaneous fistula. Conclusion: The commonest type of hypospadias is the coronal type with almost $55 \%$ of patient presenting before the age of 5 years. The commonest type of hypospadias is the coronal type (29.4\%). Urethrocutaneous fistula is the commonest complication in hypospadias surgery. The use of dermal graft for the correction of severe chordae is a reliable alternative.
\end{abstract}

Keywords: Hypospadias, Buccal Mucosal Graft, Glanuloplasty, Urethroplasty, Dermal Graft

\section{Introduction}

Hypospadias is one of the commonest urologic congenital anomalies. It is associated with three anatomical anomalies: 1. an abnormal ventral opening of the urethral meatus; 2 . Ventral curvature (chordae) of the penis; 3 . A hooded foreskin [1]. The prevalence of hypospadias is estimated to be; Europe 19.9 (range: 1-464: 100,000); North America 34.2 (6-129.8) per 100,000; South America 5.2 (2.8-110) per 100,000; Asia 0.669 per 100,000; Africa 5.9 (1.9-110); 100,000, and Australia 17.1-34.8 (2) per 100,000. About two-thirds to three-quarters of hypospadias are glanular or coronal [2]. Distal penile hypospadias may constitute about $77.2 \%$, mid-penile, $11.4 \%$; proximal penile, 11.4 [3].

The first description of urethral hypoplasia and hypospadias malformation was related to Celsius and Galen, and dates as far back as to the first and second centuries AD [4]. The renaissance of hypospadias surgery was established by Thiersch, and Duplay during the second part of the 19th century $[5,6]$. Since then, hundreds of techniques have evolved, mostly to answer the challenge of creating a functional neo-urethra. Some popular procedures include; glans approximation procedure (GAP), meatal advancement and glanuloplasty incorporated (MAGPI), tubularized incised plate urethroplasty (TIPU), Mustarde', etc. When and how to repair is a very crucial decision for the surgeon. This will depend on; type of hypospadias, whether patient is circumcised or not, presence or absence of a chordae, state of penile skin (this will depend on number of previous attempts at repair) and the experiences of the surgeon. The use of buccal mucosal graft in hypospadias repair become necessary 
in those who need to undergo a staged procedure either as an inlay or a tube. The buccal mucosa appears to be a durable source of non-genital tissue for urethral substitution, which was first introduced in 1941 by Hamby [7]. Buccal mucosal tube urethroplasty is a good single staged procedure for patients without a good or ideal urethral plate after the first repair thus reducing the number of procedures. The only disadvantage is that the urethral catheter will have to stay in longer to reduce the effects of graft contracture. Generally there is no difference in complication rates in the use of grafts and flaps in the repair of hypospadias. Adult hypospadias usually requires urethroplasty as a result of multiple failed attempt or untreated ones due to various reason. Usually a two staged repair is preferred for those who require the use of a buccal mucosa graft. This is to assure a graft take before the second stage repair [8].

\section{Main Objective}

To review the seven years results of hypospadias surgery at the 37 Military hospital mainly;

1) To determine the age of presentation for hypospadias repair.

2) To determine the complications of hypospadias repair.

3) To determine the common types of hypospadias.

\section{Method}

This was a retrospective study of patients who had hypospadias repair between the periods of 2010 to 2017 at the 37 Military hospital. Data of patients who had hypospadias repair at the urology unit was collected. A total of 51 patients were studied out of a total of 1,467 surgeries done within that period. Data on patient age, type of hypospadias, type of repair, complications were recorded. Repair was done for patients older than 6 months. All age groups were included, all hypospadias repair done before the year 2010 were excluded. Patients were seen at the out patients department, history taken, examined and some basic investigation done. Investigations included; full blood count, urine culture, and a blood urea and electrolyte. Patients were admitted a day or two before operation. All patients had general anaesthesia with a chordal block.

Decision to do a particular repair depended on; type of hypospadias, whether it was a first repair or had previous failed repair, whether the patient was circumcised or not, and the presence or absence or a chordae.

Types of repair for urethral construction included; Glans Approximation procedure, (GAP); meatal advancement and glanuloplasty incorporated, (MAGPI); tubularized incised plate urethroplasty, (TIPU); Mustarde'; buccal mucosal tube tunnelled urethroplasty.

For the correction of the chordae, a dermal graft was the main procedure of choice.

1. Gap: The glans wings is marked with a horseshoe-shaped incision (a deep U), encircling the meatus. This is kept 12 to $14 \mathrm{~mm}$ apart to ensure an adequate terminal urethra. A size 11 blade is used to raise the flap and glans wing. The terminal urethra is tubularized over a stent, placing two layers of fine running sutures subcuticularly, using 7-0 polyglycolic acid suture. With a third layer of sutures using 7-0 or $6-0$ polyglycolic acid suture were used to close the subcutaneous layer. The glans flaps is approximated with fine interrupted sutures.

2. Magpi: Starting from inside the dorsal edge of the meatus, a generous vertical incision is made to the distal end of the glanular groove. This is then closed transversely, (Heineke-Mikulicz principle), using vicryl 8-0 or 7-0 sutures.. This advances the meatus and flattens the groove. An Incision is made on the ventral skin transversely $0.8 \mathrm{~cm}$ from the coronal sulcus and meatus. The proximal edge of the meatus is lifted with a skin hook or traction suture, pulling it toward the tip of the glans to form an inverted V. The excess skin and glans tissue on the medial margins of these wings are excised to expose glans tissue in preparation for a glansplasty. The glans is approximated with 6-0 synthetic absorbable sutures. Median raphe is aligned, excess preputial skin is excised, and edges sutured with 6-0 synthetic sutures.

3. Tubularised Incised Plate Urethroplasty (TIPU): Patients with narrow urethral plates for primary tubularization. An incision is made in the midline of the plate to the level of the corporal body. This allows the urethral to spring open for subsequent tubularization.

4. Buccal Mucosal Graft: Graft were taken from inner check. This is defatted and then Tabularized or used as an inlay. The buccal tube is then tunnelled sub-dartos to the neo-meatus.

5. Mustarde: Patients for secondary tubularization with narrow urethral plates. An incision is made in the midline of the plate. This is undermined and wings raised. A proportional U- shape incision is made proximally, tubularized and then brought under the distally raised wing and buried.

Inclusion Criteria: All patients that had repair done between the ages of 6 months and 25 years.

Exclusion Criteria: All Patients with perineal hypospadias with an associated ambiguous genitalia.

Results: The commonest age of presentation and repair is before the age 5 years, which represents $54.9 \%$ (21/51). 13.7\% of these patients are below the age one. $7.9 \%$ (4/51) presented after the age of 15 years. The commonest types of hypospadias at presentation is the coronal, 29.4\%; followed by the penile $21.6 \%$. Perineal types are usually rear constituting about $5 \%$ of all hypospadias. $41.2 \%(21 / 51)$ had a Glanular Approximation Procedure (GAP). 23.5\% (12/51) had a Buccal Mucosal Tubed Tunnelled Urethroplasty (BMTTU). 21.6\% $(11 / 51)$ had dermal graft orthoplasty for correction of their chordae. $11.8 \%(6 / 51)$ had a penile transposition using the bottom-hole technique or the Reda's procedure. $25.5 \%(13 / 51)$ had chordae, 11 out of the $13(90 \%)$ was moderate to severe requiring the use a dermal graft. Two patient's chordae were corrected by just de-gloving the penis. 
Complications; $\quad$ FISTULAE $=4 \quad(7.8 \%), \quad$ FAILED REPAIR=2 (3.9\%) PROXIMAL STRICTURE=1 (1.9\%). Out of those with fistulae, two (2) of them had a buccal mucosal tube, thus $2 / 12(16.7 \%)$ of buccal mucosal tube resulted in fistulae. One fistula resolved spontaneously after about four weeks of catheterization. One had a successful repair, two are yet to be repaired, lost to follow-up. Of the two patients with failed repair, one has been repaired successfully, the other was lost to follow up. One patient had a proximal stricture, he is one of those who had the buccal mucosal tube repair. This was managed by serial dilation. Had 3 over seven months and was lost to follow-up.

Ethical approval was obtained from the institutional review board.

\section{Results}

Table 1. Age distribution.

\begin{tabular}{ll}
\hline AGE (YEARS) & NUMBER (\%) \\
\hline$<1$ & $7(13.7)$ \\
$1-5$ & $21(41.2)$ \\
$6-10$ & $12(23.5)$ \\
$11-15$ & $7(13.7)$ \\
$>15$ & $4(7.9)$ \\
TOTAL & 51 \\
\hline
\end{tabular}

Table 2. Type of hypospadias.

\begin{tabular}{ll}
\hline TYPE OF HYPOSPADIAS & NUMBER (\%) \\
\hline GLANULAR & $10(19.6)$ \\
CORONAL & $15(29.4)$ \\
PENILE & $11(21.6)$ \\
PENOSCROTAL & $10(19.6)$ \\
PERINEAL & $5(9.8)$ \\
TOTAL & 51 \\
\hline
\end{tabular}

Table 3. Hypospadias with associated anomalies.

\begin{tabular}{lll}
\hline & NUMBER & PERCENTAGE (\%) \\
\hline HYPOSPADIAS + CHORDEE & 13 & 25.5 \\
HYPOSPADIAS + CHORDEE + UNDESCENDED TESTIS & 1 & 2.0 \\
HYPOSPADIAS + UNDESCENDED TESTIS ONLY & 1 & 2.0 \\
HYPOSPADIAS + CHORDEE + CONGENITAL HYDROCELE & 1 & 2.0 \\
HYPOSPADIAS + CONGENITAL HYDROCELE ONLY & 1 & 2.0 \\
HYPOSPADIAS + PUJ OBSTRUCTION & 1 & 2.0 \\
\hline
\end{tabular}

Table 4. Type of repair.

\begin{tabular}{lc}
\hline TYPE OF REPAIR & NUMBER (\%) \\
\hline GAP & $21(41.2)$ \\
MAGPI & $2(3.9)$ \\
TIPU & $5(9.8)$ \\
MUSTARDE' & $2(3.9)$ \\
BUCCAL MUCOSAL TUBE & $12(23.5)$ \\
PENILE TRANSPOSTION (REDA'S PROCUDURE) & $6(11.8)$ \\
DERMAL GRAFT ORTHOPLASTY & $11(21.6)$ \\
\hline
\end{tabular}

\section{Complications}

\section{URETHROCUTANEOUS FISTULA. \\ 2. PROXIMAL STRICTURE. \\ 3. FAILED REAIR.}

\section{Discussion}

Hypospadias though seen very early in life, its repair has never been immediate as this does not pose any health threat to the patient. Repair from our study has ranged from six months to 32 years. Repair, from previous literature has been before the age of two years or before the child starts school. The commonest type hypospadias is the coronal type $29.4 \%$ followed by penile hypospadias $21.6 \%$. Others have however found different results at presentation. Apeadu- Mensah et al in 2007 found penile hypospadias as commonest (61\%), [9]. and Osereman et al in 2015 found distal hypospadias as the commonest (58.4\%) [10]. The GAP procedure can be used for both glanular hypospadias and coronal hypospadias.

Repair for hypospadias depends a number of factors; (1) the type of hypospadias, (2) absence or presence of chordae, whether or not patient is circumcised, (3) degree of scaring 
from previous repairs, (4) the age at repair and (5) the expertise of the surgeon. All these will determine the approach to repair and associated complications. Hypospadias repair has evolved though; urethral advancement procedures, urethral tubularization procedures, Vascularized flaps, to the use of grafts. Buccal mucosal grafts are popular due to easy access. It is a stable alternative for urethral replacement in patients with multiple failed attempts at urethroplasty where there is insufficient penile skin to be raised as flaps.

A number of studies have shown that buccal mucosa has the thinnest lamina propria layer while having the greatest native vascular supply. In contrast, mucosal cells grow rapidly so that the mucosal grafts take easily and settle with good pliability [9]. There is little data available on the use of buccal mucosal graft as a tube due to its complications [11, 12]. First, the urethral stent has to be kept in place much longer to prevent excessive graft contraction in the first two to three months. This allows the graft to be well fixed to the surrounding corpora and dartos. Second, the proximal anastomosis to the urethral meatus must be wide "diamond shaped" or well spatulated, this prevent stricture formation. The distal end for the neo-urethra must also be spatulated. With these precautions the outcome of this procedure is very good. The use of dermal graft for correction of chordae is ideal for patients with severe chordae $\left(>45^{\circ}\right)$. This can be done in a single stage on most cases, or in multiple stages. In a staged repair the first priority of the initial stage is to achieve a straight phallus. This usually adds length to the phallus. The additional penile length achieved with dermal grafting results in a dependent phallus and cosmesis preferable to that of plication only [13]. Alternatively a small intestinal submucosal (SIS), tunical vaginalis graft may be used to correct the chordae $[14,15]$. Usually patients with mild chordae $\left(<30^{\circ}\right)$ can be corrected with only degloving of the penis [16]. All the patients who had dermal grafts had 100\% graft take in a single stage. Three patients had other associated anomalies apart from the presence of a chordae. These were, undescended testis, congenital hydrocele, and a pelvi-ureteric junction (PUJ) obstruction. The patient with the PUJ was picked up about a year later when he presented with recurrent urinary tract obstruction and a CT scan picked up the anomaly.

\section{Conclusion}

The commonest age of presentation and repair is before the age of 5 year representing about $54.9 \%$ (13.7\% of these patients are below one year). The commonest type of hypospadias is the coronal type $(29.4 \%)$. Urethrocutaneous fistula is the commonest complication in hypospadias surgery. This may be related to the type of hypospadias and type of repair. The use of dermal graft for the correction of severe chordae is a reliable alternative.

\section{Conflict of Interest}

None to declare.

\section{References}

[1] David FM Thomas, Patrick G Duffy, Anthony MK Rickwood editors, essentials of paediatric urology, $2^{\text {nd }}$ edition: Informa UK Ltd 2008; 213p.

[2] A Springer, M Van Den Heijkant, S Baumann. Worldwide prevalence of hypospadias, jpurol 2015, 12. 002.

[3] Anne-Françoise Spinoit, Filip Poelaert, Luitzen-Albert Groen, Erik Van Laecke, Piet Hoebeke Department of Urology, Ghent University Hospital, Ghent, Belgium. Received: December 21, 2012; Published Online: January 09, 2013.

[4] Smith ED. The history of hypospadias. Pediatr Surg Int. 1977; 21: 81-85.

[5] Thiersch C. Uber die entstehungswise and operative behandlung der epispadie. Arch Hetkunde. 1869; 10: 20-25.

[6] Duplay S. De l'hypospade périnéoscrotal et de son traitement chirurgical. Arch General Med. 1874; 1: 613-657.

[7] Humby G. A one-stage operation for hypospadias. Br. J. Surg. 1941; 29: 84 .

[8] Muxin Zhao, Yangqun Li, Yong Tang, Wen Chen, Zhe Yang, Qiang Li, Chuande Zhou, Fengyong $\mathrm{Li}$ and $\mathrm{Yu}$ Zhou Two-stage repair with buccal mucosa for severe and complicated hypospadias in adults. Original Article. International Journal of Urology (2011) 18, 155-161.

[9] Appeadu-Mensah W, Hess A A, Hypospadias Surgery at Korle-Bu Teaching hospital, Ghana: A Review of 36 Patients. African Journal of Paediatric Surgery Vol. 4 (2) 2007: pp. 61-63.

[10] Aisuodionoe-Shadrach OI, Atim T, Eniola BS, Ohemu AA. Hypospadias repair and outcome in Abuja, Nigeria: A 5-year single-centre experience. Afr J Paediatr Surg 2015; 12: 41-4.

[11] Sahin C, Seyhan T. Use of buccal mucosal grafts in hypospadia-crippled adult patients. Ann. Plast. Surg. 2003; 50: 382-6.

[12] Dessanti A, Iannuccelli M, Ginesu G, Feo C. Reconstruction of hypospadias and epispadias with buccal mucosa free graft as primary surgery: more than 10 years of experience. J. Urol. 2003; 170: 1600-2.

[13] Lindgren BW, Reda EF, Levitt SB, Brock WA, Franco. Single and multiple dermal grafts for the management of severe penile curvature. J Urol. 1998 Sep; 160 (3 Pt 2): 1128-30.

[14] Snodgrass W, Prieto J. Straightening ventral curvature while preserving the urethral plate in proximal hypospadias repair. $\mathrm{J}$ Urol (2009) 182: 1720-5.10.1016/j.juro.2009.02.084.

[15] Castellan M, Gosalbez R, Devendra J, Bar-Yosef Y, Labbie A. Ventral corporal body grafting for correcting severe penile curvature associated with single or two-stage hypospadias repair. J Pediatr Urol (2011) 7: 28993.10.1016/j.jpurol.2011.03.008.

[16] Paulo R. M. Moscardi, Rafael Gosalbez, Miguel Alfedo Castellan Management of High-Grade Penile Curvature Associated With Hypospadias in Children. Front Pediatr. 2017; 5: 189. Published online 2017 Sep 4. doi: 10.3389/fped.2017.00189. 